Árvore de Pré-Requisitos da Teoria das Restrições para a programação de atividades em gestão de projetos de expansão física multissetorial para
hospital de alta complexidade

AUTORES: Helena Barreto dos Santos, Ana Paula Coutinho, Antonio Carlos Gruber, Carlos Alberto Ribeiro, Carlo Sasso Faccin, Daniel Writzl Zini (dzini@hcpa.edu.br)

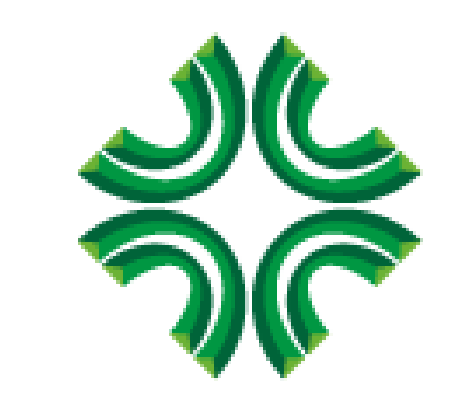




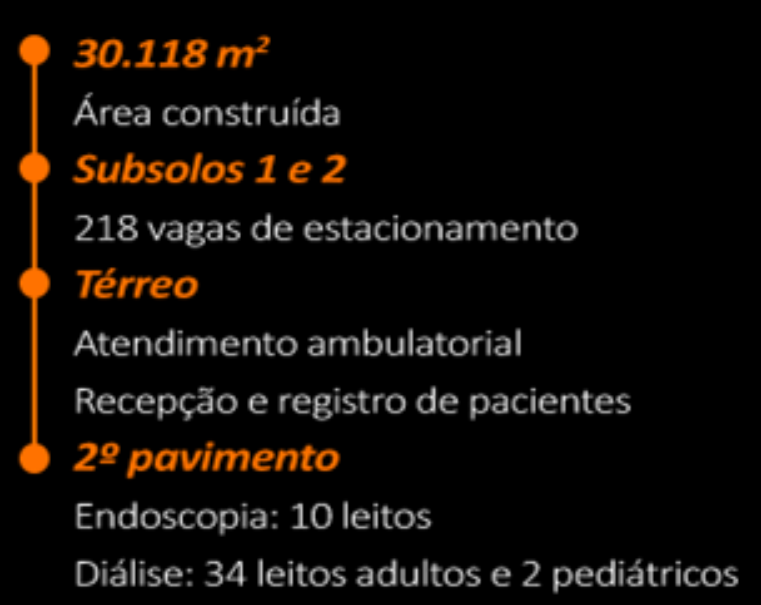

$53.981,65 \mathrm{~m}^{2}$

Área construída

504 vagas de estacionamento Subsolos 1 e 2

Emergência com 5.159,92 m²

Térreo

2o pavimento

Hemodinâmica: 4 salas

Vestiário de barreira

Anestesiologia

3o pavimento

Recuperação Pós-anestésica:

90 leitos e 60 poltronas

\section{0 pavimento}

Bloco Cirúrgico e Centro Cirúrgico Ambulatorial:

41 salas de procedimentos / Ressonância magnética 5o pavimento

Centro de Material Esterilizado

Laboratório de Patologia

Salas de aula e de estudos

6ㅇ pavimento

Centro de Tratamento Intensivo: 55 leitos

$7^{\circ}$ pavimento

Centro de Tratamento Intensivo: 55 leitos

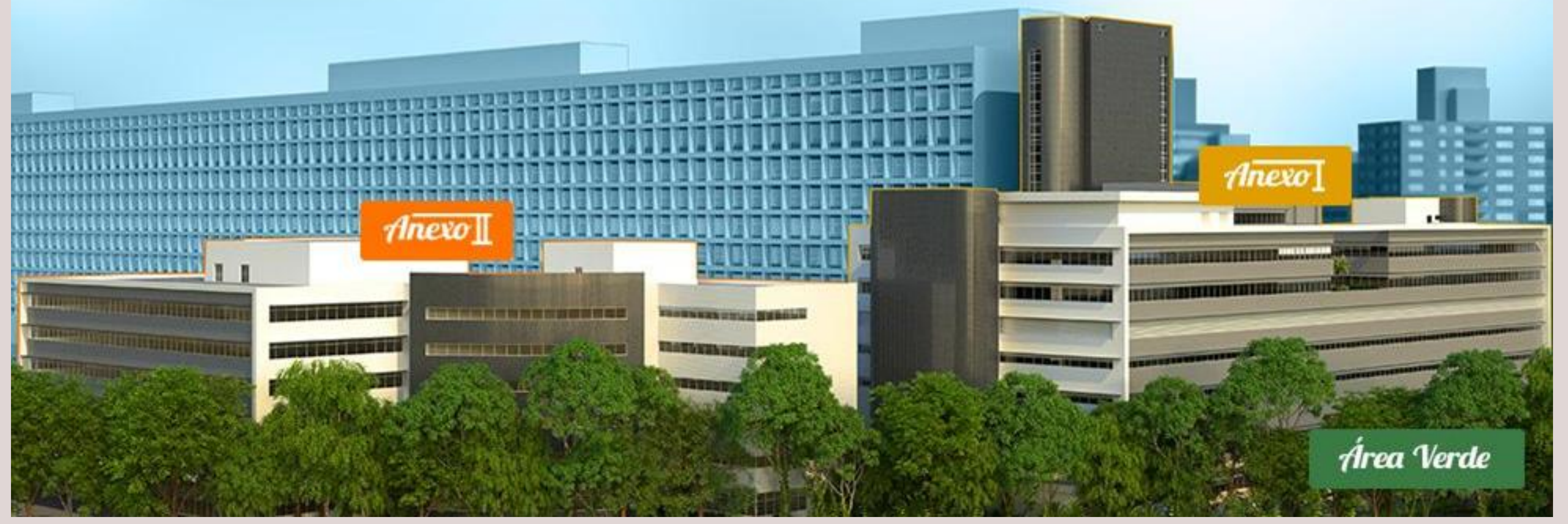

NECESSIDADES:

$\rightarrow$ sequência

$\rightarrow$ recursos

$\rightarrow$ requisitos 
GRUPO:

$\rightarrow$ diretoria

$\checkmark$ médica

$\checkmark$ enfermagem

administrativa $\rightarrow$ hotelaria

$\rightarrow$ arquitetura

$\rightarrow$ engenharia

$\checkmark$ civil

$\checkmark$ produção
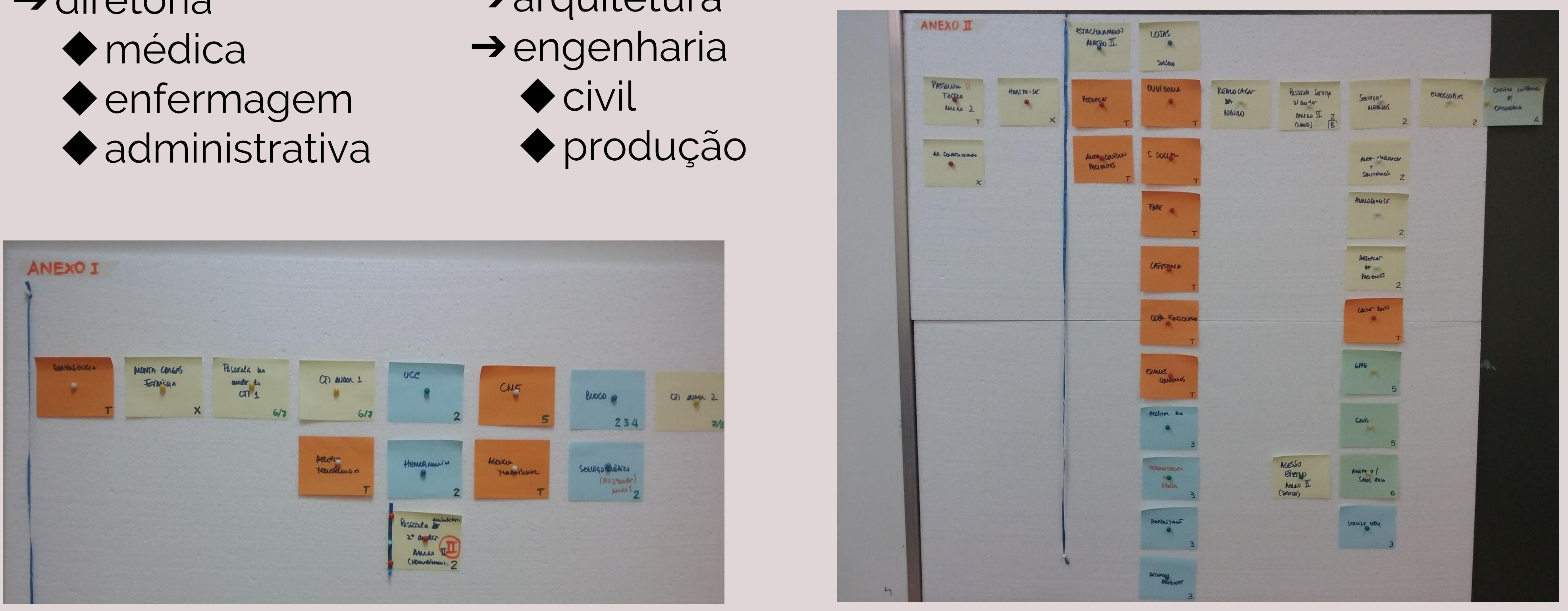

FERRAMENTA:

$\rightarrow$ Árvore de Pré-requisitos da Teoria das Restrições 
ÁRVORE DE PRÉ-REQUISITOS PARA PROGRAMAÇÃO DE ATIVIDADES RESULTADO: ÁRVORE DE OCUPAÇÃO

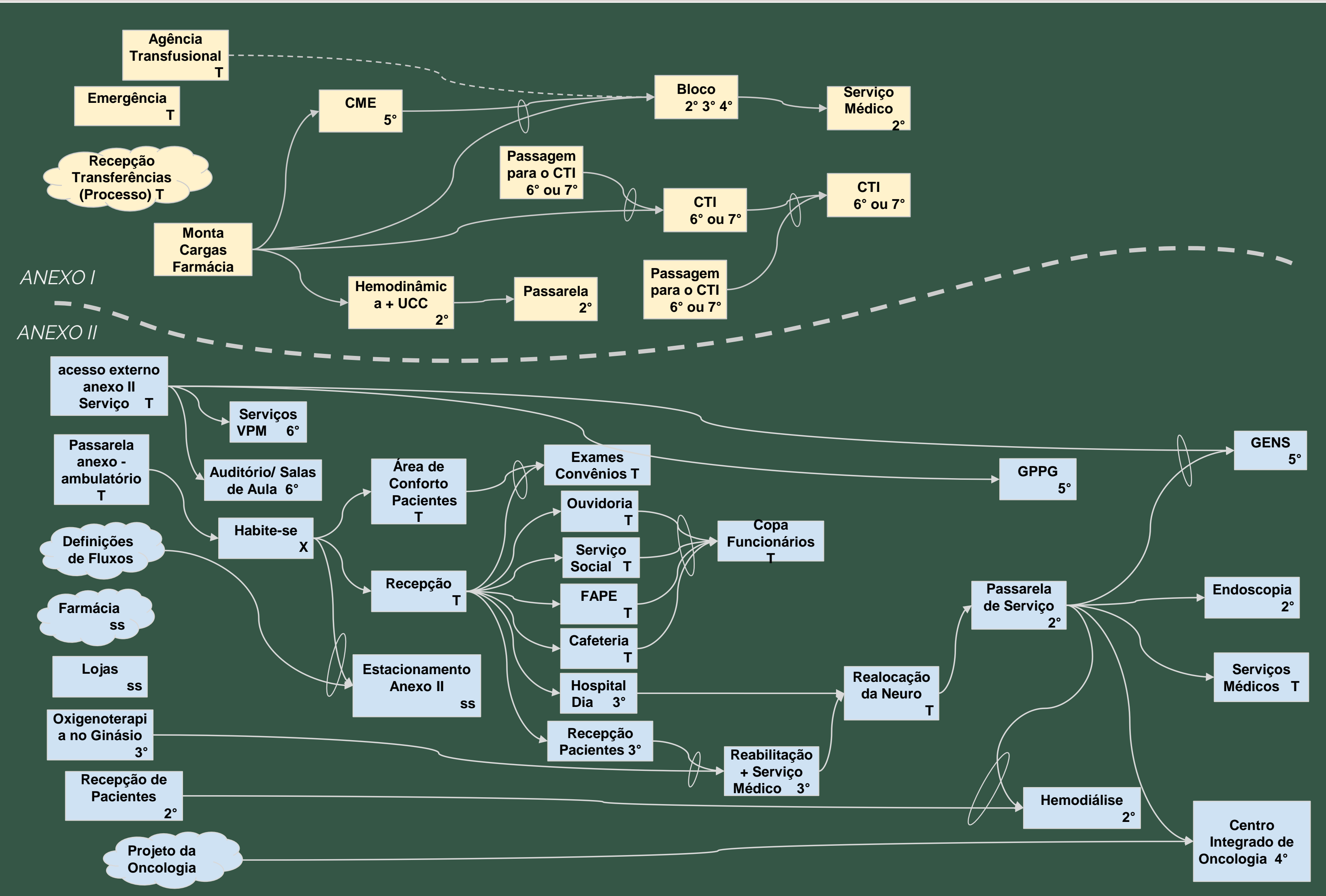




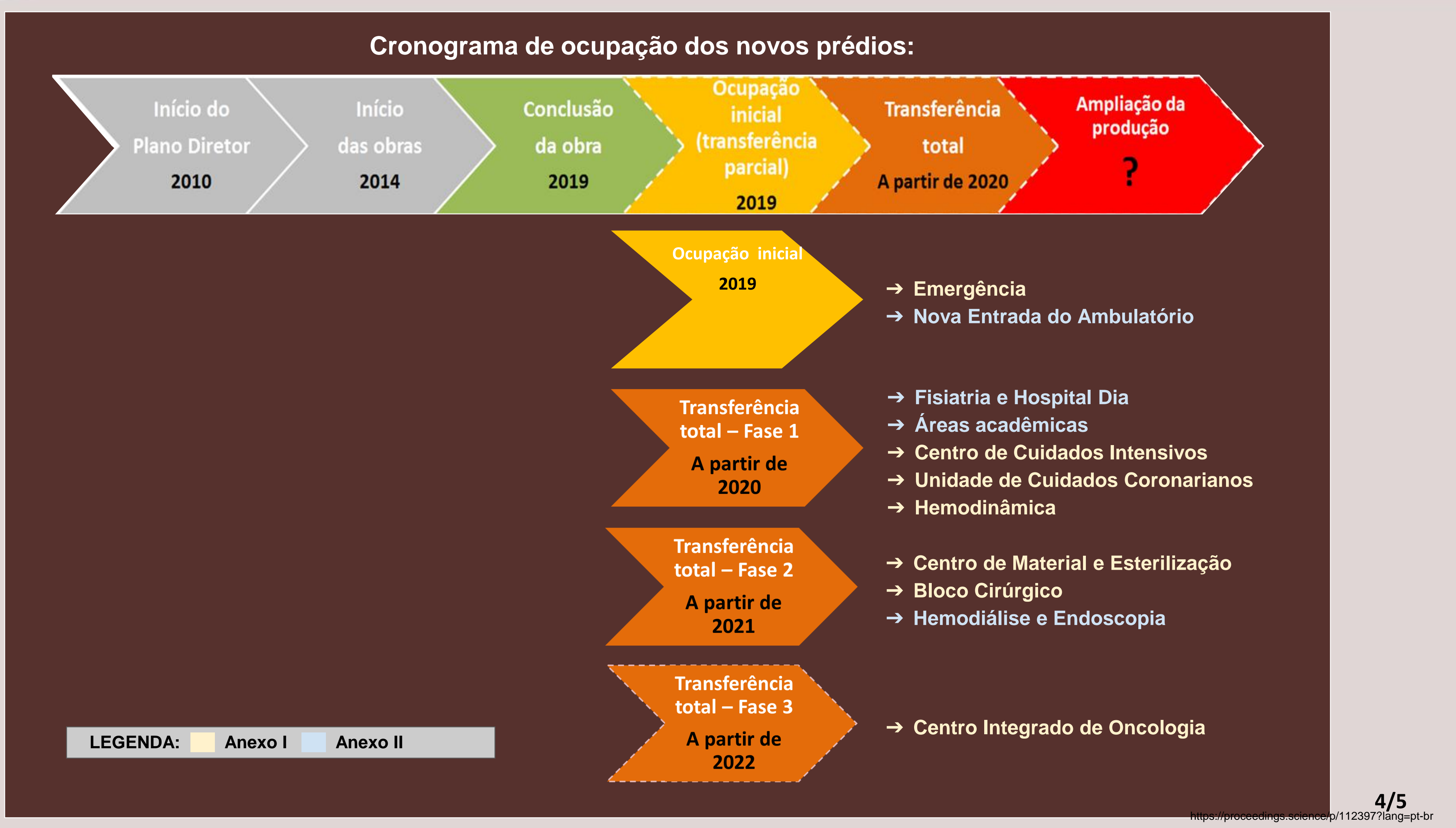


$\checkmark$ POSSIBILIDADE DE ATENDER A REQUISITOS:

* Legais

* Financeiros

* Operacionais

PRIORIZAÇÃO:

* Compras

* Projetos de Engenharia

* Licitações

$\checkmark$ EXECUÇÃO:

* Mantendo o Atendimento

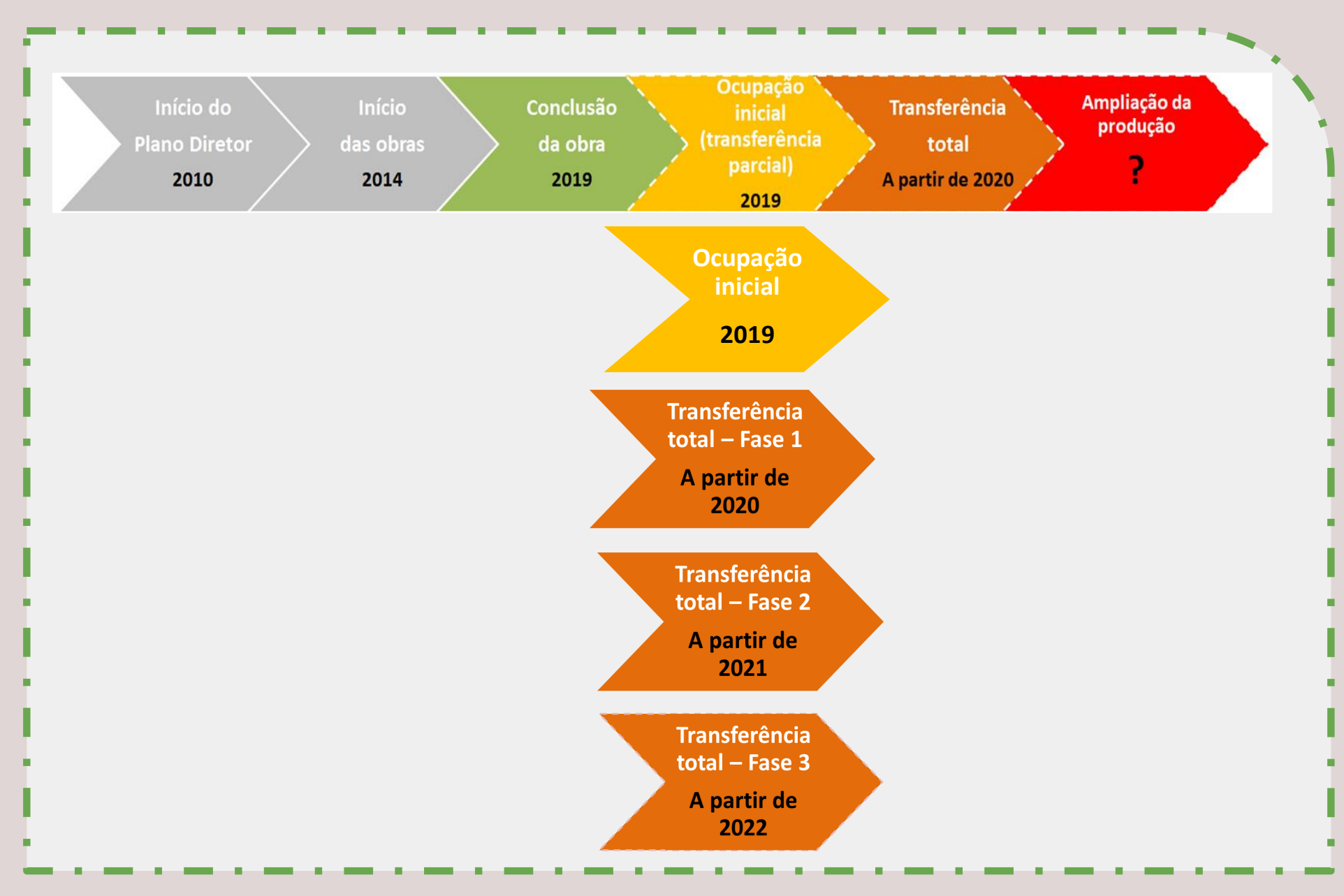




\section{Árvore de Pré-Requisitos da Teoria das}

Restrições para a programação de atividades em gestão de projetos de expansão física multissetorial para hospital de alta complexidade

AUTORES: Ana Paula Coutinho, Antonio Carlos Gruber, Carlos Alberto Ribeiro, Carlo Sasso Faccin, Daniel Writzl Zini

(dzini@hcpa.edu.br)

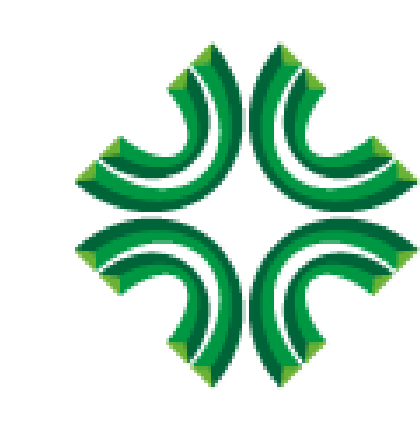

